This essay is part of IJARBM's special issue

"Contemporary Applied Business Research

in Light of Standard Academic Literature".

\title{
The Consumer as Homo Sapiens: On the Practical Relevance of Research On Consumer Behavior
}

\author{
Atilla Wohllebe \\ atilla.wohllebe@gmail.com \\ WR Institute of Applied Sciences, Hamburg, Germany \\ https://doi.org/10.51137/ijarbm.2022.3.1.5
}

\begin{abstract}
For economics, Nobel laureate Richard $\mathrm{H}$. Thaler has called for understanding humans more as Homo sapiens and less as homo economicus in order to bring research closer to reality. This essay applies his critique to the study of consumer behavior and its relevance in corporate practice. The author criticizes that the findings of consumer behavior research are often too abstract and too strongly related to a specific context to derive direct practical recommendations for action from a company's perspective. The causes identified are the use of sometimes oversimplified models and the collection of too narrow samples. In order to align business research with regard to consumer behavior more closely to practice, the use of more comprehensive models and larger samples, greater standardization and a stronger focus on meta-analyses are suggested to bring together findings from different contexts more effectively and make them comparable.
\end{abstract}

Keywords - Applied Research, Application-Oriented Research, Marketing, Homo sapiens, Homo economicus

\section{Background: Homo Economicus as Aberration of Economics}

Perhaps one of the most important constructs of economics has been disproved. The "Homo Economicus", long used as the basis of many theories and models, does not exist. Human action is not (always) rational; it is not (always) oriented to maximize one's own economic benefit. Instead, says Thaler, referring to the findings of psychology, people are often irrationally optimistic, overconfident, infer from themselves to others, and ignore all the things they don't know. On the basis of this observation, the U.S. economist Thaler called in 2000 for a shift in economics from "homo economicus" to "homo sapiens" and meant the greater inclusion of the human psyche in economic theories and models. (2000). For the "libertarian paternalism" developed on this basis, Thaler later receives the Nobel Prize (Zschäpitz, 2017).

From today's perspective, Thaler's criticism of the economic theories that had been widely accepted up to that time can be seen as a fundamental

The Consumer as Homo Sapiens:

On the Practical Relevance of Research On Consumer Behavior 
questioning of what practical use science can provide that is based at its core on an assumption that is not true - the existence of homo economicus.

In his critique, Thaler makes clear reference to economics. Nevertheless, a similar pattern of argumentation is also conceivable for business administration and, in particular, for marketing and the study of consumer behavior. Similar to the simplified "homo economicus" in economics, who always functions in the same way, business administration is often based on a highly simplified understanding of consumers. This is a major challenge with regard to the practical relevance and applicability of the results of consumer behavior research in corporate contexts.

\section{Challenge: Practical Relevance of Research on Consumer Behavior}

Consumer research can be regarded as part of marketing and marketing as part of business administration. Furthermore it can be assumed that business administration as a science pursues the purpose of creating knowledge that serves to fulfill the business purpose in companies. Assuming this, the research of consumer behavior is per se aimed at generating knowledge for practical application.

Accordingly, the findings of consumer behavior research must actually be usable in practice. This means that it must be possible to derive clear business recommendations from the findings.

In fact, however, the practical relevance of many scientific papers in the sense of the previously elaborated claim seems to be limited.

As an example, an article published in 2019 in "The International Review of Retail, Distribution and Consumer Research" examines the mediating role of last mile delivery in the relationship between online retail experience and customer satisfaction. In the section of "managerial implications", the authors elaborate that "last mile delivery should be used as a tool for generating competitive advantage for e-retailers" (Vakulenko et al., 2019). Therefore, managers must "commit to a cooperative approach to e-retail customer experience design, and coordinate their activities with complementary partners" (Vakulenko et al., 2019). But how does this finding help in practice, and what concrete recommendations can be derived from it? Is the fact that the performance of the logistics company on the last mile has an effect on the overall satisfaction of the customer with the online purchase really a more than merely trivial finding from a practical point of view?

Similarly, the concrete practical benefit of one's own work can also be questioned. In 2020, an article appeared in the "International Journal of Interactive Mobile Technologies" that examines the influence of customer satisfaction on a retailer's willingness to install an app [4]. Along with digitization, mobile apps have gained relevance in many areas in recent years (Deckert \& Wohllebe, 2021; Diez, 2020; Papadakis et al., 2020; Ross, 2020). The article concludes that "the existing, satisfied customer base of a company [could be] could be a promising target group if new app users are to be acquired with limited resources" (Wohllebe et al., 2020). Nevertheless, the 
article leaves open how the concrete acquisition of existing customers for app installations can look and also contains numerous limitations with regard to the sample. The respondents all come from a geographically limited area (Germany) and the answers refer to apps from a single industry (retail). In this respect, the findings may not be transferable to other geographic areas, nor to other industries. But what practical value do the results have for a retail company in Japan or a bank in Germany?

In fact, in consumer surveys, the sample drawn is likely to always lead to limitations.

\section{Limitations Due to Focus: Models \& Samples as Constraints}

Deriving clear business management recommendations for action from research seems fundamentally difficult. After all, every company is in its own unique situation. This situation is determined, for example, by the industry, the sales markets or the cost structures - companies find themselves in complex environments. Claiming the practical applicability of the research results, this is probably an almost unsolvable dilemma of business research.

Two main reasons can be identified for this: On the one hand the use of samples, on the other hand the use of models.

The already mentioned use of samples leads to the fact that results always arise on the basis of a socio-demographically specific part of the total population - and in this respect initially only apply to the specific geographical area, the specific age group, the specific gender combination, the cultural group, the industry or the respective point in time.

The second reason for limitations in the practical applicability of research results is the models on which the results are based. It is inherent in the concept of a model that it always represents only a partial section of a simplified reality. For example, the "Technology Acceptance Model" (TAM) used in business information systems to research technology use refers exclusively to the technology itself. It considers the perceived use and the perceived simplicity of use and derives the behavioral intention to use from this over several stages (Davis, 1985). But what about other factors such as trust in the technology or the opinion a potential technology user has of the technology's developer? Couldn't a positive opinion of the developer possibly also positively influence whether a consumer of the technology would want to use it?

\section{Suggestions: Larger Models, Broader Samples, Standardized Methods and Meta-Analysis}

Probably the most important limitations of consumer behavior research can be traced back to the use of models and samples. Both lead to the fact that the results of the research, which are mostly developed in very specific contexts, can only be transferred and applied to a limited extent. In this re- 
spect, consumer behavior research practically approaches the "truth" with small triple steps. At the same time, the "truth" is not only dynamic, but also complex and therefore hardly to be grasped in its entirety.

But how can this problem be solved?

I would like to raise a total of three thoughts on this. All three thoughts are to be understood under the premise that research in the context of business administration - and thus also in the research of consumer behavior - must primarily take place in order to gain concrete insights for implementation in practice.

1. To gain insights that can be applied as directly as possible in practice, more comprehensive models and large samples are needed that allow companies in different contexts to actually apply them. A good example of this is the extension of the TAM to the TAM2 (Venkatesh \& Davis, 2000).

2. To simplify the transfer of findings to different contexts, standardized methods and models are needed so that quantitatively obtained findings can be compared even more easily. In this respect, the globally used TAM is already a good example - in terms of technology use - because it makes it easier to compare findings from different contexts.

3. More meta-analyses are needed to make better use of the comprehensive (cf. 1) knowledge that exists in many places (cf. 2) to make it more accessible to practice. These studies should primarily focus on compiling knowledge generated based on a specific method (e.g. TAM2) for individual subareas (e.g., mobile apps in the health context) from different contexts (e.g. geographic spaces).

All in all, these remarks show that not only economics relies on the homo economicus construct, which was rightly criticized by Thaler. In business administration and consumer behavior research, too, there are constructs and models that help to understand reality, but do not (and cannot) represent it completely. Accordingly, the findings of the research can only be used directly in practice to a limited extent, with simplifying models and overly pointed samples limiting this transferability of the findings. The concluding three thoughts, which build on each other, and of these in particular the plea for a stronger focus on meta-analyses, are a suggestion as to how consumer behavior research can be geared more strongly to practice, understanding the consumer not just as a static set of decision rules but as a homo sapiens.

\section{References}

Davis, F. (1985). A technology acceptance model for empirically testing new end-user information systems-Theory and results [PhD Thesis].

Massachusetts Inst. of Technology.

The Consumer as Homo Sapiens:

On the Practical Relevance of Research On Consumer Behavior 
Deckert, R., \& Wohllebe, A. (2021). Digitalisierung und Einzelhandel:

Taktiken und Technologien, Praxisbeispiele und Herausforderungen

(1st ed.). Springer Gabler.

https://www.springer.com/de/book/9783658330897

Diez, E. (2020). Managing A Veterinary Practice: A Guide To Organizational Culture In Veterinary Practice. International Journal of Applied Research in Business and Management, 1(1), 18-26.

https://doi.org/10.51137/ijarbm.2020.1.1.2

Papadakis, S., Vaiopoulou, J., Kalogiannakis, M., \& Stamovlasis, D. (2020). Developing and Exploring an Evaluation Tool for Educational Apps (E.T.E.A.) Targeting Kindergarten Children. Sustainability, 12(10), 4201. https://doi.org/10.3390/su12104201

Ross, F. (2020). Hearing Aid Accompanying Smartphone Apps in Hearing Healthcare. A Systematic Review. Applied Medical Informatics, 42(4). https://ami.info.umfcluj.ro/index.php/AMl/article/view/792

Thaler, R. H. (2000). From Homo Economicus to Homo Sapiens. Journal of Economic Perspectives, 14(1), 133-141.

https://doi.org/10.1257/jep.14.1.133

Vakulenko, Y., Shams, P., Hellström, D., \& Hjort, K. (2019). Online retail experience and customer satisfaction: The mediating role of last mile delivery. The International Review of Retail, Distribution and Consumer Research, 29(3), 306-320.

https://doi.org/10.1080/09593969.2019.1598466

Venkatesh, V., \& Davis, F. D. (2000). A Theoretical Extension of the Technology Acceptance Model: Four Longitudinal Field Studies. Manage- 
ment Science, 46(2), 186-204.

https://doi.org/10.1287/mnsc.46.2.186.11926

Wohllebe, A., Ross, F., \& Podruzsik, S. (2020). Influence of the Net Promoter Score of Retailers on the Willingness of Consumers to Install Their Mobile App. International Journal of Interactive Mobile Technologies (IJIM), 14(19). https://doi.org/10.3991/ijim.v14i19.17027

Zschäpitz, H. (2017, October 9). Richard H. Thaler: Dieser Nobelpreis verändert unser aller Leben. DIE WELT. https://www.welt.de/wirtschaft/article169446770/Dieser-Nobelpreisveraendert-unser-aller-Leben.html 